\title{
SMART GRID INTEGRETED WITH HYBRID RENEWABLE ENERGY SYSTEMS
}

\author{
Ömer AYDIN ${ }^{1, ~ *}$ Zafer DEMIR $^{2}$ \\ ${ }^{1}$ Graduate Education Institute, Eskişehir Technical University, Eskişehir, Turkey \\ ${ }^{2}$ Porsuk Vocational School, Eskişehir Technical University, Eskişehir, Turkey
}

\begin{abstract}
The growing world population and fossil fuel reserves have been aimed at alternative searches as energy sources due to a decreasing curve. The rate of formation of Fossil fuels does not exhibit a parallel formation of the amount of consumption according to the years. Nowadays, no matter how many alternative suggestions are revealed, there is no way to choose them yet. Despite the use of fossil fuels such as coal, oil and natural gas in energy production, the rapid depletion of these resources has increased the direction of us to renewable energy sources. The key advantage of renewable energy sources is the ability to create a hybrid system with other energy sources. Hybrid systems allow the combined use of different energy sources and the integration of renewable energy sources into the existing system. This study provides examples of hybrid renewable energy systems and information on how to integrate into existing systems. One of the most important applications to increase the use of renewable energy resources is the systems that are used together with different energy sources and are called hybrids. Today, it has become mandatory to analyze various working conditions as well as in large power systems of renewable energy-induced hybrid systems that are widely used.
\end{abstract}

Keywords: Hybrid systems, Renewable energy, Energy sources

\section{INTRODUCTION}

Electricity production is done by different type of power plants. Although power plants can be defined by various categories we will use one definition in this study due to congress subjects. Renewable Energy Sources (RESs) and Non- Renewable Energy Sources (NESs). NESs are known as traditional power sources. Those are not usefull anymore. They creates air pollution and several the environmental probles. Traditional power sources are also limited on the earth. The RESs are used to refer to power generating methods that don "t pollute, abundant in amount on earth and that are friendlier to the environment. RESs are solar, wind, hydro energy, biomass, hydrogen, geothermal power.

RESs are the basic need of the green and clean world. Air quality index is going to be worse every year. For improving global air quality index, whole world is serious to generate their electrical energy from the RESs. Moreover, RESs are also reducing dependency on generation from fossil fuels [1].

Many countries are agreed and signed in Paris Agreement for very important goals for reducing carbon emissions to save the planet in 2015. The use renewable energy sources for electricity should be the first step for a better world.

\section{HYBRID RENEWABLE ENERGY SYSTEMS}

The major advantage of renewable energy sources is that it can form a hybrid system with other energy sources. In general, hybrid energy systems are systems where two or more different energy generation systems work together to feed electrical or thermal load.

Hybrid renewable energy systems are available that can operate on or off the grid. Systems operating independently of the grid are used in conjunction with diesel generators to generate energy in rural and

*Corresponding Author: omeraydin@eskisehir.edu.tr

Received: 11.10.2019 Published: 16.12.2019 
remote areas. In hybrid energy systems, electricity generation (photovoltaic panels, wind turbines, hydro turbines, generators) and storage battery tools are required to meet the electrical energy demand of a remote or close facility, a rural or urban house, a farm and even a community. how many are brought together.

Figure 1 shows a hybrid renewable energy system consisting of solar panels and wind turbines. In general, hybrid energy systems are intended to ensure the reliability of the electrical energy supply and/or because of the possibility that the renewable energy source may be cut off at any time in an energy system composed of a single renewable energy source other than the main purpose of supplying the load. They are designed to reduce the unit cost of electrical energy in an energy system consisting of a conventional energy source.

A small "hybrid" electric system that combines home wind electric and home solar electric (photovoltaic or PV) is in Figure 1.

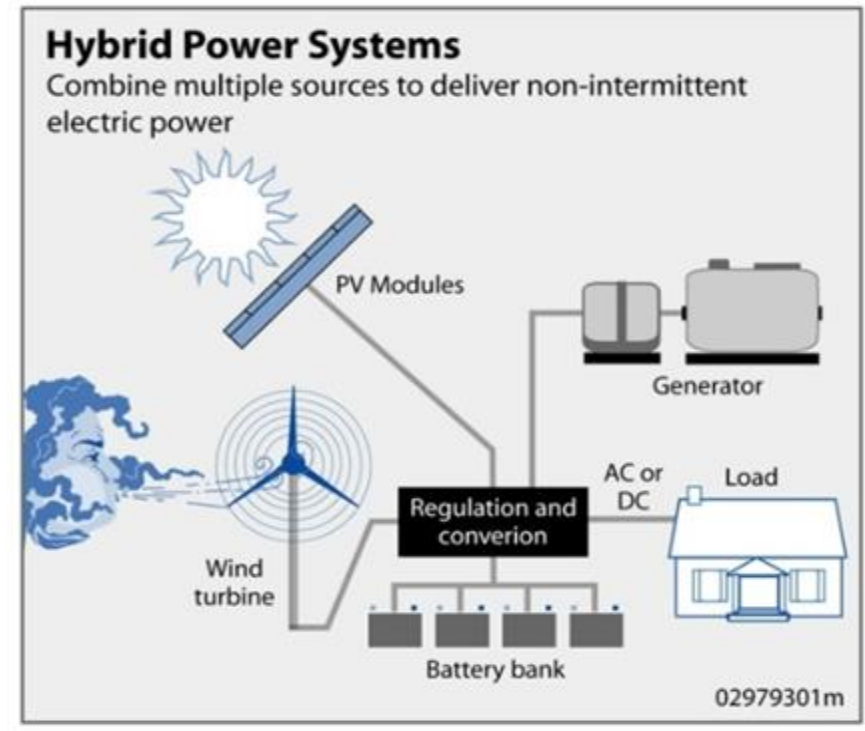

Figure 1. Hybrid Power Systems (energy.gov)

Let's compare the place of hybrid renewable energy in the global market and compare traditional/hybrid renewable energy facilities.

Global market: A hybrid renewable energy system is essentially an energy generation facility that combines two or more independent renewable technologies. The three main types of hybrid renewable plants observed in the global market:

- Solar and wind hybrid

- Wind with energy storage, currently small

- Solar, wind and energy storage hybrids, mostly in demonstration phase

Hybrid plants offer numerous advantages over traditional solar panels and wind farms. The comparison between traditional and hybrid renewable power plants can be made with three main parameters:

- Production Costs

- System Reliability

- Operational Flexibility [2]. 


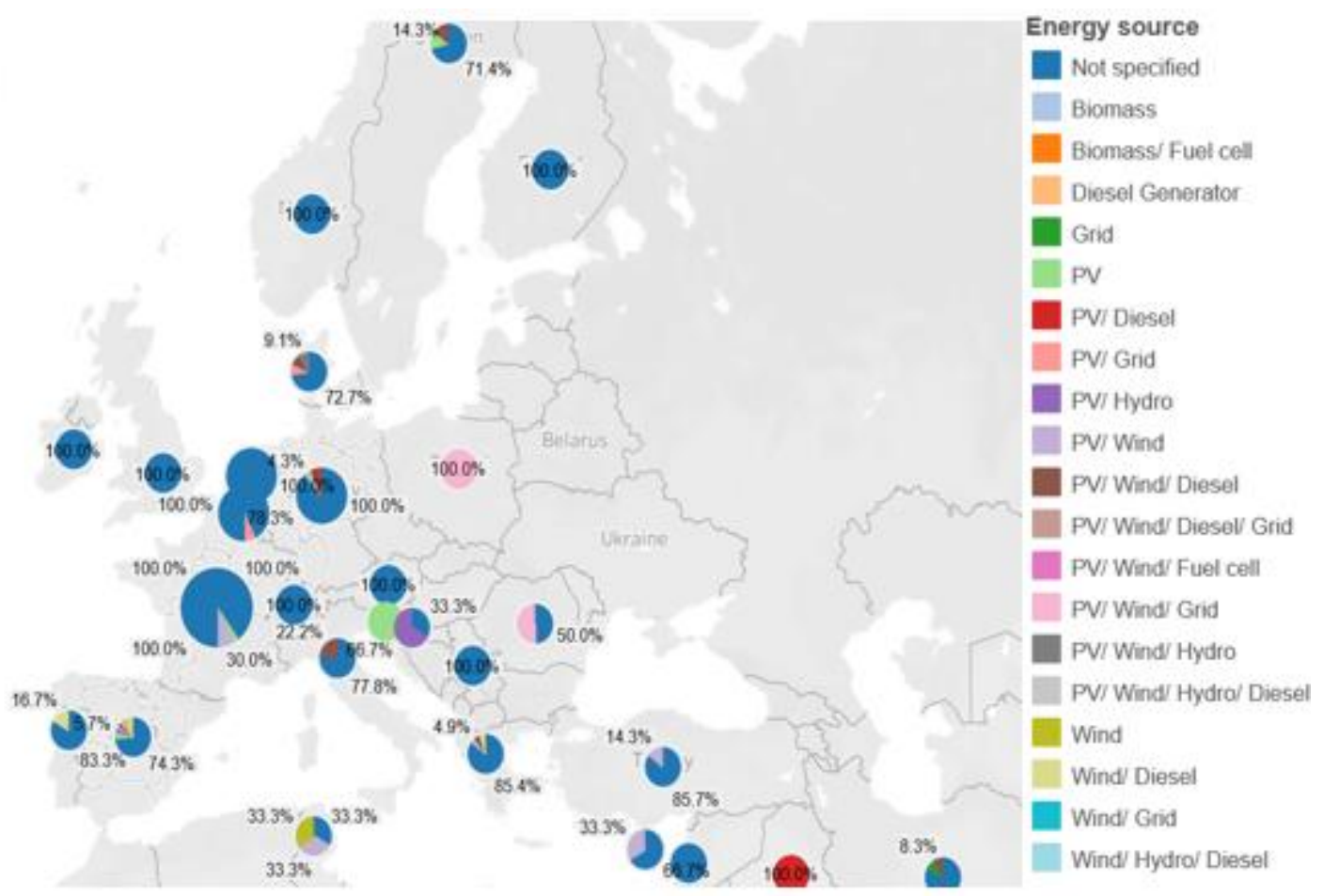

Figure 2. Studies On Renewable And Hybrid Energy Systems In Europe (http://electrifyme.org/dynamiccharts)

Research on hybrid and non-hybrid renewable energy systems in Europe is observed. According to the research, it is observed that studies on PV / Grid, PV / Hydro, PV / Wind / Diesel and PV / Wind are concentrated. Today, the use of fossil fuels to generate energy is harmful to nature in terms of carbon emissions. The most popular view in the world is renewable energy sources due to low carbon emissions and the way they are used. When we look at the research, we focus on the hybrid or non-hybrid renewable energy systems of the world trend. Since renewable energy systems depend on natural conditions, it is not possible to obtain continuous efficiency from each of them. For example, sunbathing times may vary, and if the source is a hybrid wind / PV / diesel system, it provides wind continuity when there is no sunbathing. In such a hybrid system, when there is no wind and sunbathing, the diesel generator is activated to ensure supply security. The European continent hybrid or non-hybrid renewable energy research distribution map shows which countries plan for the installation of systems, figure 2.

The use of hybrid renewable energy systems are increasing day by day. Figure 2 shows the percentage of studies in Europe. Advantages and disadvantages of hybrid renewable energy systems are important to decide what to do for power plants.

\subsection{Advantages Of Hybrid Renewable Energy Systems}

\subsubsection{Continuous power supply}

\section{Hybrid Solar and Battery System:}

This is another thriving sample. Hybrid solar systems provide uninterrupted power as the connected batteries store energy. This is also useful if there is no sun and energy aren't produced during the evening and night. The batteries feature a backup instrument and the uninterruptible power supply continues. 
Wind and Solar Hybrid System:

This is a thriving sample. On days when wind speeds are insufficient or inefficient, solar energy can alternatively be utilized. Thus, the continuity of energy production in the system is ensured.

\subsubsection{Making the best use of renewable energy sources:}

\section{Hybrid Solar and Battery System:}

Since batteries are connected to the system to store energy, there is no waste of excess energy generated on sunny days. Therefore, these systems make the best use of renewable energy, store energy on a good day, and use stored power on a bad day. Balance is maintained.

\section{Wind and Solar Hybrid System:}

A small hybrid electrical system combines wind or photovoltaic solar technologies, or can use a single system to offer many advantages. In the summer, when the sun's rays are strongest and brightest, the wind speed is low. In the winter months when there is less solar energy, the wind speed is high. Balance is maintained.

\subsubsection{Low maintenance cost}

\section{Hybrid Solar and Battery System:}

Hybrid solar systems have low maintenance costs compared to conventional generators. Fuel is not used and does not require frequent service. [3]

\section{Wind and Solar Hybrid System:}

PV systems are the systems with the lowest maintenance and failure costs due to the absence of moving parts. For this reason, PV system manufacturers can give a lifetime of about 25 years. Advances in power electronics converters and automatic control systems, which improve the operation of hybrid energy systems and reduce maintenance requirements, have made hybrid systems practical and economical.

\subsubsection{High efficiency}

\section{Hybrid Solar and Battery System:}

Hybrid solar systems operate more efficiently than conventional generators that waste fuel under certain conditions. Hybrid solar systems work efficiently in all conditions without wasting fuel.

\section{Wind and Solar Hybrid System:}

Particularly suitable for industrial plants. The minimization of the annualized cost system and the minimization of the loss of power supply probability is an important advantage. [4]

\subsubsection{Power management}

The energy supply of a hybrid system can be self-adjusting according to the question of whether it is a high power plant or a house that requires less power, depending on the devices to which they are connected.

\subsubsection{Low emission}

Hybrid energy systems aim to reduce the emission rate by maximizing the use of renewable resources. Clean and renewable resources have several advantages, such as less dependence on fossil fuels, the availability of free resources, and the reduction of harmful emissions to the atmosphere. 


\subsection{Disadvantages of Hybrid Renewable Energy Systems}

\subsubsection{Complex control process}

Operation, interactions and coordination of different energy sources should be controlled. This may complicate the control process.

\subsubsection{High installation cost}

Although the maintenance cost is low, the initial investment in the installation of hybrid energy systems is high.

\subsubsection{Reduced battery life}

Batteries that are connected to the system are often subject to heat, rain, etc. They may have a lower lifespan than they are exposed to such natural elements.

\subsubsection{The number of connectable devices is limited}

The number of devices you can connect to the hybrid energy system is limited and varies from system to system.

\subsubsection{Design of hybrid renewable energy systems}

For a given hybrid energy system, this design stage would be to determine:

- The type of renewable energy system to be included.

- The number and capacity of renewable energy units to be installed.

- Whether a back-up unit, such as diesel generator, fuel cell etc. would be included in the system.

- Whether energy storage would be integrated into the system.

- Whether the system is stand-alone or grid connected. [5]

The choice of technology for the hybrid renewable energy system to be installed is the first consideration in the design phase. The weather conditions of the region to be selected are an important selection criterion especially for wind turbines. Different combinations of renewable energy sources have to be considered according to weather conditions and feasibility studies are required for these combinations. Optimization techniques should be considered for the feasibility study. After this work, efficiency, economy and reliability should be in question.

When dimensioning system components, many parameters or limits directly affect operation. For example, initial investment costs, economic power of the system over time, greenhouse emission conditions, and most importantly energy supply security. If the system is over-dimensioned, the system can be left alone with high system costs and the installation of the system can be abandoned.

\section{GRID INTEGRATION OF RENEWABLE ENERGY SYSTEMS}

Depending on the scale of production, renewable energy systems can be integrated into transmission or distribution networks. Wind power plants, which are a large-scale part of renewable energy generation, can be connected directly to the transmission system and small-scale distributed generation can often be connected to medium or low voltage systems. Before designing the system for both interconnection types, a detailed analysis should be performed to face the different challenges within it. 
The energy produced by small renewable generation systems cannot be directly connected to the grid. A kind of interface between production and distribution network is required. For example, the power electronics-based DC-AC converter must be between the mains and PV panels.

Although direct connection to the AC network is possible via small hydro or wind based induction generators, it is necessary to use a power electronics converter to avoid concerns about the initiation of transients, energy conversion efficiency and power quality.

Electricity and natural gas, which are considered as the main inputs in the industry, have started to use different controllability methods in their consumption due to the rapid changes in the markets. The energy sector in the world is changing. During these changes, new requirements emerged for low energy efficiency, security of supply and energy quality, and distributed production. Smart networks have created an alternative way to become a modern solution for these important topics. It is a structure that integrates supply and consumption behaviors, one of the most important elements of smart grids. To summarize the objectives of smart networks; continuity in use, reduction of loss and leakage, efficient use of energy resources and sustainability of data flow.

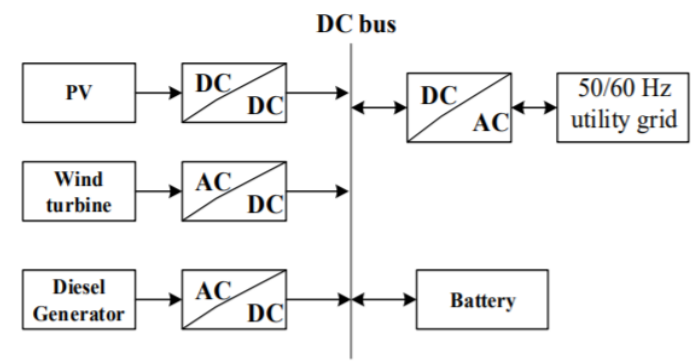

(a)

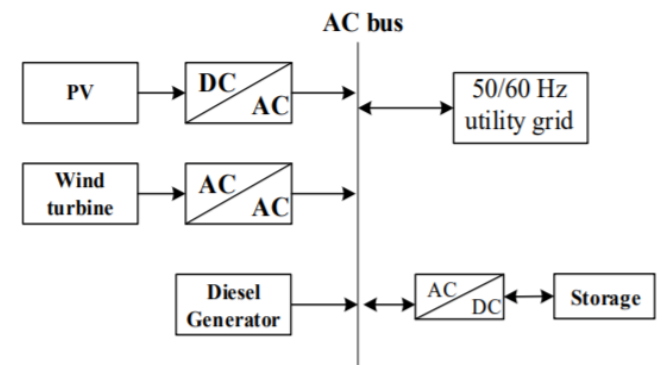

(b)

Figure 3. (a) Centralized dc-bus, (b) centralized ac-bus[4]

Figure 3 shows examples of centralized DC and AC bus. The hybrid system, for example, appears to use a diesel generator as well as renewable energy sources such as PV and wind. Battery is used as energy storage in the system. Ac power sources such as wind and diesel generators are first converted to dc before powering the main dc bus to power the rectifiers. An inverter is responsible for supplying the ac network from this dc bus.

When looking at the centralized ac bus, the energy sources and the battery are mounted in one place and connected to a main ac bus bar via the appropriate power electronics.

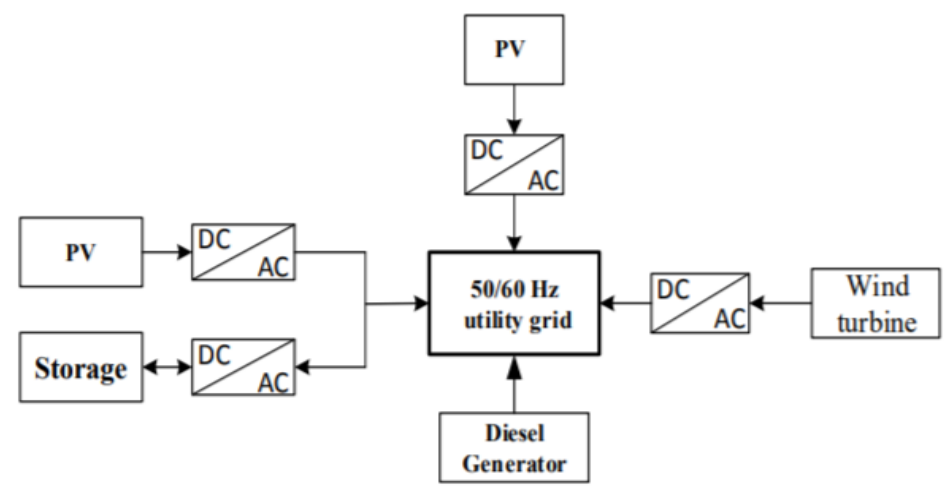

Figure 4. Distributed ac-bus[4] 
In Figure 4, the distributed ac bus is observed. In this system, power supplies need not be installed close to each other. Resources can be installed in different geographical locations and connected to the network separately.

The starting point of smart grids was electricity distribution systems. Nowadays, application studies for natural gas, which is one of the main inputs, are continuing rapidly. When we consider natural gas, one of the main energy inputs, with the logic of smart grids applied to electricity distribution systems; Natural gas consumption amount, pressure and temperature value can be kept under control. As in the control of electricity consumption, the regulation and controllability of the natural gas market is ensured.

\section{SMART GRID}

Many engineering studies are needed for the installation of smart grids. Especially interdisciplinary studies are of great importance. Communication is one of the important building blocks of smart networks. In particular, the installation of two-way communication in these systems needs to be done carefully. Structurally intelligent networks need to establish a close link between the supply side and the demand side.

Conventional systems will continue to be the cornerstone of smart grids. However, studies on the development of conventional systems are continuing. We observe that the development of microprocessor-based imaging, protection, control and data acquisition devices is becoming more important today with the incorporation of different disciplines into conventional systems. However, it is observed that smart grids are open to further development.

With increasing power demand, load profiles on the system are forced. Here are a few of the most important features we need to connect; network stability, security, transmission and use of low-cost production resources. In order to keep the above-mentioned concepts in balance, the installation structure of the smart networks must be flexible.

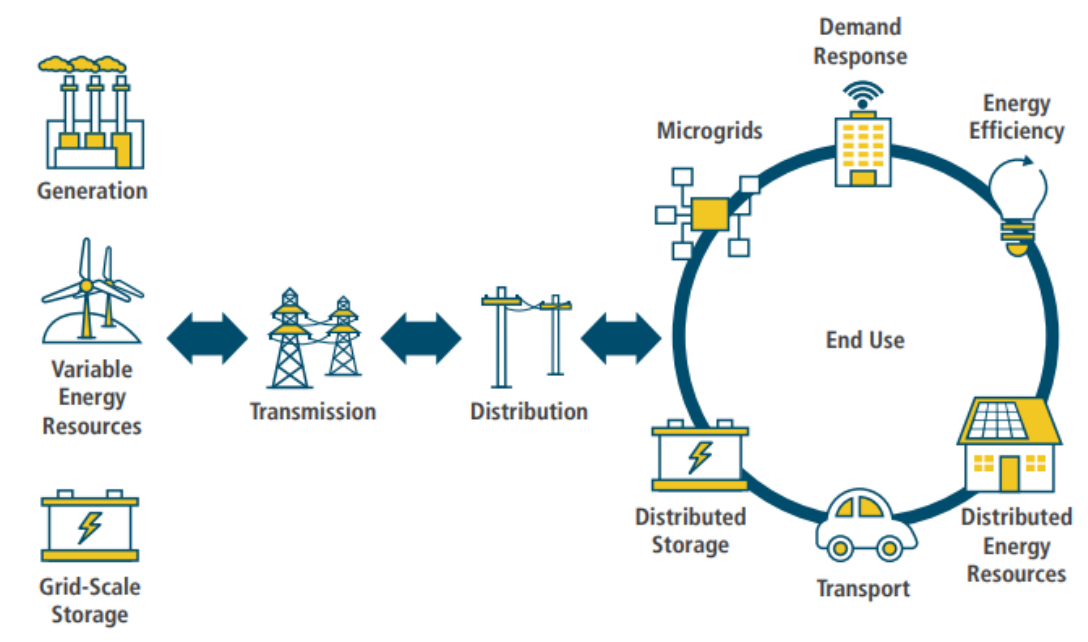

Figure 5. Overview of the Smart Grid

(Transforming The Nation's Electronic System: The Second Installment Of The Qer 2017)

Ensuring traceability of the whole system, self-decision making and switching are the infrastructure of smart networks. To summarize the general features of smart grid;

- Controlling intelligent switchgear centers

- Ensuring energy continuity and responding to power outages

- Easy commissioning after failure

- Intelligent adaptation to power generation systems 
System reliability is the most important issue for distributed power generation systems. After providing security of supply, optimization and energy efficiency will be the most important issues to be investigated. The future energy structure and virtual power plants need to have systems that define and control small power plants as a single power plant.

Figure 6 shows the structure of smart grids by comparing the past and the future of transmission and distribution lines. Communication between the consumer and the producer is the most prominent in the two comparisons. Since conventional systems do not communicate, control of existing production is not ensured and since demand is not clearly defined, companies perform production according to certain criteria. In the classical structure, while centering comes to the forefront, centering in smart grids is distanced from centering. While it is observed that the fossil resources are included in the system in the classical structure, it is stated that renewable energy sources are included in the system in smart grids.

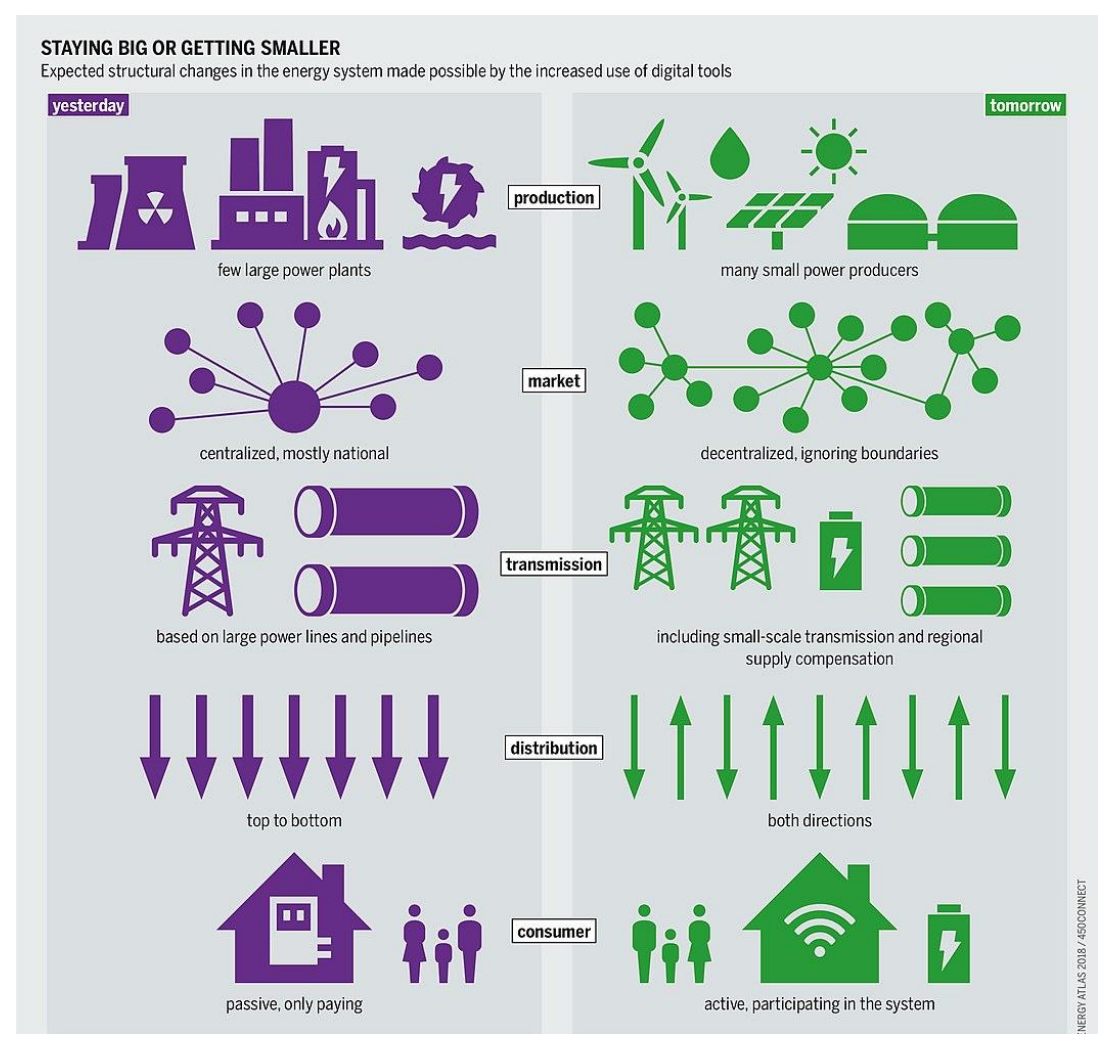

Figure 6: Comparison of conventional and smart grid (Energy Atlas 2018)

As mentioned earlier, control of the distribution networks will be difficult as the interconnections of renewable energy generation plants cause load increases and voltage fluctuations. Uncontrolled systems can have big negative effects on energy quality. Necessary control and control measures shall be taken along with continuous traceability in distribution networks. The regulating structures mentioned can control the voltage, active power and reactive power manually or automatically. Production systems, transformer structures and capacitors, which are familiar with conventional systems, will be used for control. As a result, power flow quantity and directions can be monitored and limit overshoots can be intervened quickly and accurately with these systems. In addition, the traceability of network losses will prevent many problems.

\section{SMART GRID INTEGRETED WITH HYBRID RENEWABLE ENERGY SYSTEMS}

A scalable and reliable renewable energy based smart grid model with generic components is shown in Figure 7. The primary grid in the form of large generator with its excitation system and secondary control 
serves as the main utility supplying power using conventional transmission lines. On the other side, distributed generators in the form of renewable energy sources are connected through power electronic converters and interfaces to the grid using static or dynamic coupling. The supervisory control ensures the continuation of power supply during dynamic events. For example, during blackouts or service hours on the main grid side or transmissions lines, the system transfers to islanded mode and continues to supply power through renewable energy systems. If the dynamics keep changing, distributed generators (or micro-grids) keep operating in synchronization with the primary grid. [6]

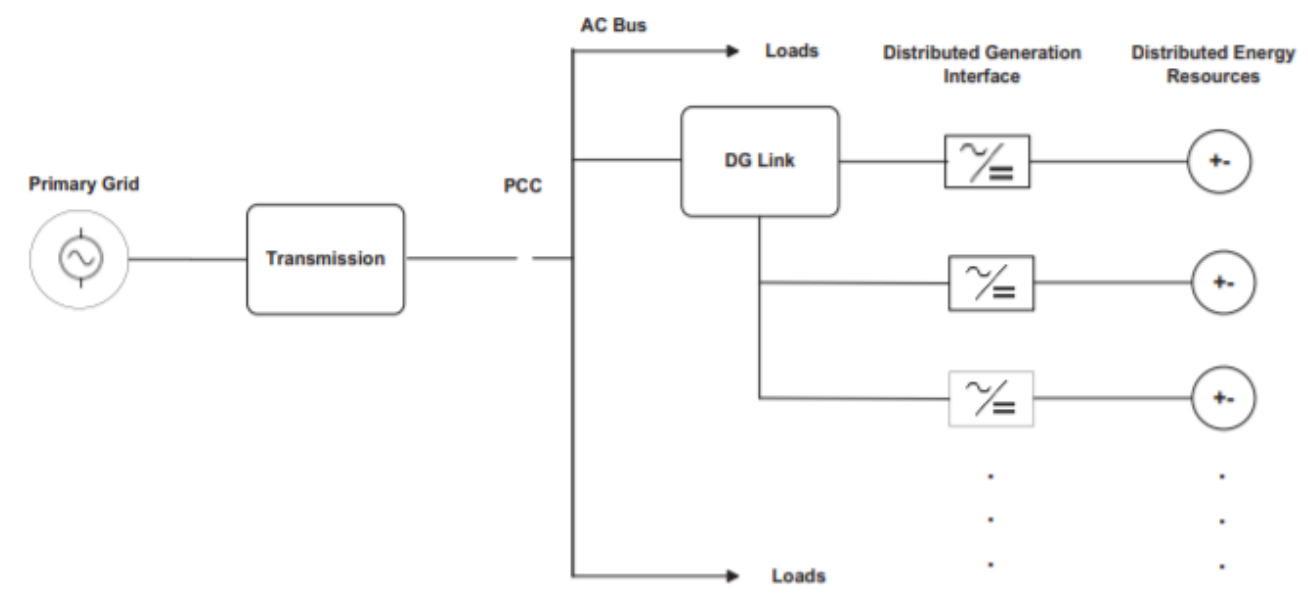

Figure 7. Scalable model for smart grid with renewable energy sources [5]

To count the components of distributed power systems; first, there must be an energy source that provides power, secondly the energy source must be incorporated into the system by an inverter or a converter.

Micro grids, which can be seen as subheadings of smart grids, provide us with great advantages in eliminating the problems in the integration of renewable energy sources to the main grid. When we redefine micro grids under this heading, we can say that multiple customers, power generation generators and energy storage systems are connected together. In fact, these systems are small-scale electric power generation and distribution systems. When we examine these systems, it is possible to use electrical energy as well as thermal energy (heating-cooling).

Cyber-physical system design based approaches to improve the resilience, efficiency and transient performance of a smart grid system are becoming popular.[7]

\subsection{Energy Storage Systems for Smart Grid}

Energy storage systems in smart grids and micro grids; plays an effective role in dealing with hourly changes in demand and price. Energy storage systems support different applications such as:

a. It can be used as an uninterruptible power supply for mobile phones, laptops and mobile electronic devices that we use in our offices or daily life.

b. It can be used for energy storage for stationary electricity generation and distribution systems. For example, national electricity grid, military facilities and so on.

c. Most importantly, they function in a wide range of applications. For example; they are the power source for vehicles in land, air, sea and space.

In energy storage technologies; storage capacity, energy availability, discharge time, efficiency, 
durability and independence.

Examples of electrical energy storage technologies include capacitors, ultra capacitors and superconducting magnetic energy storage technologies.

\subsubsection{Capacitors}

Energy storage technology that releases electricity stored in electrostatic form as electrical energy. These devices can charge and discharge cycles of hundreds of thousands of times without disturbing their existence. Capacitors have been used primarily for consumers' small electronic devices, but are increasingly being developed for powering weapons and commercial electric vehicles. Currently, increasing energy intensity is among the research objectives. [8]

\subsubsection{Ultra Capacitors / Super Capacitors}

Capacitance values are higher than normal capacitors and voltage limits are lower than other capacitors. They can store 10 to 100 times more energy in electrolytic capacitors. They have very fast charging capabilities. In addition to being more efficient than batteries, they have a longer life and do not require maintenance.

\subsubsection{Superconducting Magnetic Energy Storage}

It is one of the most important energy storage techniques. Superconductivity is the name given to the transfer of electrical current by some materials without any resistance. Superconductors are materials with zero resistance. In these technologies, the energy consists of a coil of superconducting wires wrapped in ring form. Excess electricity is supplied to this coil and stored as a magnetic field ready for use at any time. The efficiency of the system is $90 \%$ or more and the response time is very short (milliseconds). [7]

As you can see in figure 8, PV, supercapacitor and battery application is given as an example of SIMULINK model for energy storage systems.

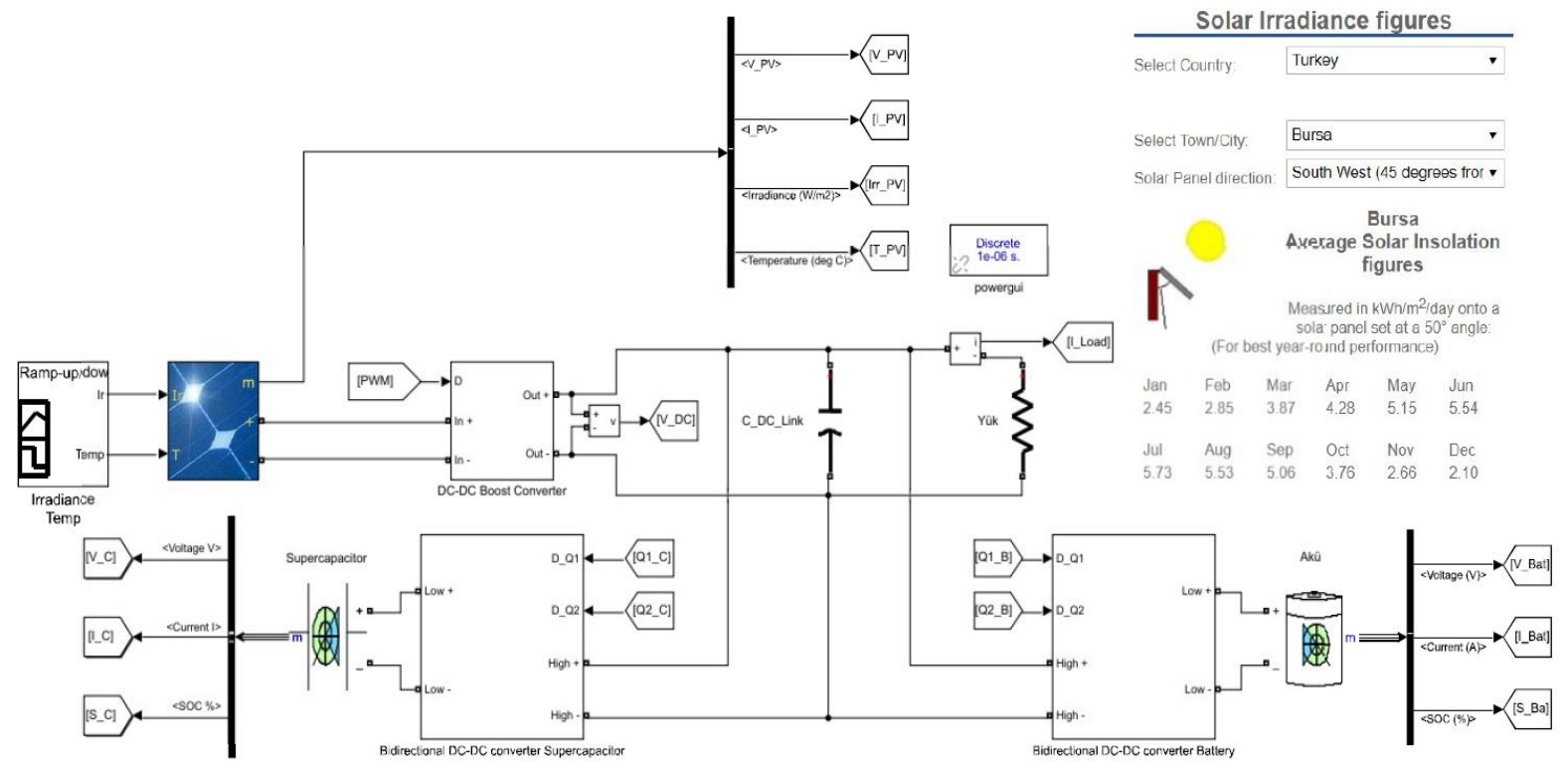

Figure 8. Supercapacitor / Battery / PV hybrid system SIMULINK model

The three energy sources in the system are connected to the dc bus station via the dc-dc converter. The system simulation results for a PV selected from the SIMULINK library can be as in Figure 8. 


\section{CONCLUSION}

In this study, approaches and information about hybrid renewable energy systems and smart grid connected renewable energy systems are given. As renewable energy sources are the future of humanity, hybrid power systems are important structures of this future. When we examine the advantages and disadvantages of hybrid systems, it is seen that they have more advantages.

Continuous power supply, the best use of renewable energy sources, low maintenance cost, high efficiency, better power management, low emission are basic advantages. Whereas complex control process, high installation cost and length of depreciation, reduced battery life, a lot devices are disadvantages of hybrid sytems. however, we must use and develop renewable energy hybrid systems, taking into account that fossil energy resources will be depleted regardless of their disadvantages. As these systems are developed smart grid systems will be better. Controlling intelligent switchgear centers, ensuring energy continuity and responding to power outages, easy commissioning after failure, intelligent adaptation to power generation systems will give to the consumers better power quality.

The smart grids needed today can be used in the charging stations of electric vehicles and can offer an easy way to integrate renewable energy sources into the grid. It should be preferred to provide a fast and reliable solution to the problems that arise from the need side producing its own electricity. The biggest impacts of renewable energy sources are; environment friendly and increase system reliability and stability. We may encounter problems in the areas of modeling, planning and integration of renewable energy sources. The important question is how to model these energy sources.

Energy storage systems are inseparable part of smart grid. Energy storage is important for charging many devices, especially the charging of electric vehicles. Establishment of electricity networks that are exclusively supplied from renewable sources will develop hybrid systems. Finally, we wish governments to give priority and incentives to renewable hybrid power systems.

Therefore, the integration of renewable energy resources into the intelligent grid system will help to meet the increasing demand for electrical energy effectively, taking into account all the challenges and the best possible solutions to reduce them.

As a result of the study, we can say that governments should focus on smart grid and hybrid renewable energy applications. They need to that follow the new technologies, change the electricity transmission and distribution infrastructure. Due to the decreasing fossil fuels, energy supply reliability needs to be ensured from renewable energy technologies. This awareness should be disseminated and the consumer side should be educated and included in this system.

\section{REFERENCES:}

[1] O Singh, S Rajput. Mathematical Modelling and Simulation of Solar Photovoltaic Array System. RAINS-2016. 978-1-4673-8819-8.

[2] Gonzalez FD, Sumper A, Bellmunt OG, Robles RV, A review of energy storage technologies for wind power applications, Renewable and Sustainable Energy Reviews, 2012-16/4: 2154-2171.

[3] Hatata AY, Osman G, Aladl MM, An optimization method for sizing a solar/wind/battery hybrid power system based on the artificial immune system, Elsevier Sustainable Energy Technologies and Assesments, 2018 Vol:27:83-93. 
[4] Bilal O, Sambou V, Ndiaye PA, Kebe CMF, Ndongo M, Optimal design of a hybrid solar-wind battery system using the minimization of the annualized cost system and the minimization of the loss of power supply probability, Elsevier Renewable Energy, 2010 Vol:35: 2388-2390.

[5] Md. Ibrahim, Abul Khair, Shaheer Ansari, A Review of Hybrid Renewable Energy Systems for Electric Power Generation, Int. Journal of Engineering Research and Applications ISSN: 22489622, Vol. 5, Issue 8, (Part - 1) August 2015, pp.42-48.

[6] Ahsan Shahid, Member IEEE, Smart Grid Integration of Renewable Energy Systems, 7th International Conference on Renewable Energy Research and Applications, Paris, France, Oct. 1417, 2018, DOI: 10.1109/ICRERA.2018.8566827.

[7] Shahid A, A cyber-physical approach for stochastic hybrid control and safety verification of smart grids, IEEE PES Innovative Smart Grid Technologies (ISGT), Asia, 2014.

[8] Behçet Kocaman, The Technologies of Energy Storage on Smart Grids and Microgrids, Bitlis Eren Üniveristesi Fen Bilimleri Dergisi, 2(1), 119-127, 2013 